\title{
Article
}

\section{Analysis of the Window Views of the Nearby Façades}

\author{
Samo Drobne ${ }^{1}\left(\mathbb{D}\right.$, Martina Zbašnik-Senegačnik ${ }^{2}$, Živa Kristl ${ }^{3}$ (D) Ljudmila Koprivec ${ }^{2}$ and Alenka Fikfak ${ }^{2, *}$ (D) \\ 1 Faculty of Civil and Geodetic Engineering, University of Ljubljana, Jamova Street 2, 1000 Ljubljana, Slovenia; \\ samo.drobne@fgg.uni-lj.si \\ 2 Faculty of Architecture, University of Ljubljana, Zoisova Street 12, 1000 Ljubljana, Slovenia; \\ martina.zbasnik@fa.uni-lj.si (M.Z.-S.); ljudmila.koprivec@fa.uni-lj.si (L.K.) \\ 3 European Faculty of Law, New University, Delpinova Street 18/b, 5000 Nova Gorica, Slovenia; \\ ziva.kristl@epf.nova-uni.si \\ * Correspondence: alenka.fikfak@fa.uni-lj.si; Tel.: +386-1-2000-777
}

Citation: Drobne, S.; Zbašnik-

Senegačnik, M.; Kristl, Ž.; Koprivec,

L.; Fikfak, A. Analysis of the Window

Views of the Nearby Façades.

Sustainability 2022, 14, 269. https://

doi.org/10.3390/su14010269

Academic Editor: Antonio Caggiano

Received: 14 November 2021

Accepted: 24 December 2021

Published: 27 December 2021

Publisher's Note: MDPI stays neutral with regard to jurisdictional claims in published maps and institutional affiliations.

Copyright: () 2021 by the authors. Licensee MDPI, Basel, Switzerland. This article is an open access article distributed under the terms and conditions of the Creative Commons Attribution (CC BY) license (https:// creativecommons.org/licenses/by/ $4.0 /)$.

\begin{abstract}
The view from the window is an important parameter of living comfort. Previous studies have defined several important characteristics of views, but there are very few studies that addressed window views in dense urban environments and their influence on the perceptual elements of the view. The scope of the study was to define the influence of design elements in window views that can trigger negative reactions from viewers. In our study the questionnaire survey was used as a method for obtaining the research data. A group of architecture students who participated as respondents selected different reactions to views and reasons for such responses. Only the window views that received poor responses were further investigated. The results were statistically analyzed according to the most frequent responses and the variability of responses. The homogeneity of the groups of responses as well as the groups of reasons was tested using the Fischer-Snedercor test. The analysis showed that the negative response to a window view depends not only on the short distance between the buildings, but also on the visual aesthetics, especially the composition quality, the surface characteristics and the maintenance of the observed building. The results show that interventions, especially natural elements such as vegetation, can increase the dynamics of the window view.
\end{abstract}

Keywords: window view; urban densification; visual aesthetic; perception of view; multi-disciplinarity

\section{Introduction}

Ensuring visual access to the outside world is essential for human well-being. Windows brings natural light indoors and provide a link to aesthetic and natural elements outdoors [1]. People generally prefer positions in rooms with a window view. If they have a choice between an office with or without windows, they will choose an office with a window view $[2,3]$. Similarly, people in a restaurant will choose a table near a window and a more expensive hotel room with a nice view [4]. So what features of the window view can attract or disturb people?

\subsection{Reaction to Window View}

Daylight is an important parameter for indoor living comfort, as people spend a large part of their time indoors. An important aspect of visual comfort is not only the degree and quality of daylight, but also the quality of outdoor views [5-9]. Recently, many studies have focused on the perception of natural and urban views [10]. Numerous studies have shown that a natural view is the most desirable and that proximity to nature can significantly improve quality of life $[5,11]$. In addition, a view of the outdoors can relieve boredom, mundanity, and claustrophobia [9]. Residents who can see trees from their homes are more satisfied with their lives [11]. Several studies have shown that contact with nature also improves overall life and job satisfaction [7,10,12-17]. Kaplan and Kaplan [5] claim that looking at nature is relaxing and even has restorative potential. Even during the 
COVID-19 epidemic lockdown, the sight of vegetation reduced levels of anxiety, anger, fear, moodiness, boredom, irritability and sleep disturbance [18].

In addition, studies suggest that looking at nature has positive effects, while looking at urban scenes, commercial landscapes and industrial areas increases feelings of sadness and decreases attention $[12,19]$. Patients who had a view of a brick wall experienced a longer postoperative hospital stay, a higher number of minor postoperative complications and a higher number of doses of strong analgesics compared to patients who could observe nature through a window [6]. Laumann et al. [20] also found that the urban environment, e.g., main pedestrian zone, bus/train station, rush hour, is less restful than the natural environment. They also observed [21] that looking at an urban environment such as a pedestrian zone, bus station and busy roads led to a higher heart rate in a group of observers than in the group observing a natural environment. The researchers also investigated whether residents of university dormitories with more natural window views would perform better on tests of directed attention than those with fewer natural views. The results showed that natural views led to higher scores for directed attention than urban views but had no effect on mood [22].

\subsection{Urban Density}

A study in semi-urban and rural areas in southern Sweden has shown that flat dwellers depend on having green spaces with different features close to their homes in order to be satisfied with their neighborhood [23]. The issue of having access to green spaces, nature, open space, etc. in cities is undoubtedly related to urban density and growing population. Higher density is a tool for the development of a sustainable urban system that saves space and energy, increases the diversity and intensity of social, commercial and cultural contacts, and enables the rational organization of service activities, social infrastructure and public transport [24,25]. However, many authors believe that the term "density" alone does not say much about the functioning of the urban system. When it comes to the quality of urban space, which includes the attitude towards the "facade view", density is treated as the user's perception of the space and its dimension. However, the normative quantities of the built environment and the definition of density according to the principles of densification and compact place making are rather abstract and indefinable. Gehl et al. [26] say that cities and buildings with modest dimensions, with narrow streets, small outdoor spaces and elaborate details are experienced much more intensely and closely by users. These spaces are usually experienced as intimate, warm and personal. In contrast, large open spaces, wide streets and tall buildings are often perceived as cold and impersonal. Perceived density depends strongly on a psychological state that is very personal and subjective, and not only on relevant physical variables. It depends above all on the feeling that there is sufficient or insufficient space available for a particular activity at a particular time [27]. Urban densification as a concept built on the development of today's cities through compact and more efficient use of space is at odds with social distancing and the increase in the extent of open public space. However, social distance in the relationship to a window view has another meaning: the provision of a personal space for the observer and a sense of connection between the surroundings and the observer. From the point of view of ensuring a multifaceted anthropological experience, all the above definitions of density and densification of urban space confirm the need to distance oneself from the neighboring building, and the possibility of perceiving it as part of the urban system and not just as the observed façade within a few meters. When we deal with the built environment in the context of the urban system, we move to the level of urban design criteria. These can be divided into three basic categories: measurable or quantitative criteria (utilization, building, spaciousness, density, insolation), non-measurable or qualitative criteria (accessibility, flexibility, importance of space, vitality) and context or general compatibility (coherence, architectural and aesthetic aspect, principle of view, presence of the past, importance of space, diversity, humane scale, hierarchy of urban criteria). Design and external efficiency refer to the arrangement of the buildings, the landscape architectural design and the 
surroundings, and architectural design includes the architectural style, the façades and the details [28]. For our research, the concept of general compatibility is particularly important (coherence, architectural and aesthetic aspect, principle of views, presence of the past, importance of space, diversity, human scale, hierarchy of urban criteria and architectural design).

\subsection{Providing Information}

The view from the dwelling has a direct impact on the health and quality of life of residents, and there is a need for a technical and systematic review to secure the right to quality of viewing in housing complexes that are becoming denser and taller [29]. A carefully designed view from a window can enhance the physiological and psychological well-being of the occupants of the house.

Architecture outlines the interior space and separates it from the outside world. The façade, with its openings, is the element that enables constant interaction between indoor and outdoor environment. The larger the window areas, the more space is exposed to external influences [30]. Through the window there is also a constant interaction with the environment, which is full of visual information about the weather and events. According to Kaplan [15], they also provide access to aesthetics and natural features. An important element that provides a quality view and user satisfaction is also greenery. Schmidt and Säumel [31] say that in Berlin high-rise housing estates, vegetation is perceived as an extremely positive factor, trees more than groups of shrubs. The view of green spaces from a high-rise housing estate improves the well-being of city dwellers [32]. Kley and Dovbishchuk [11] even found that the absence of green elements in the window view in urban areas increases the likelihood of considering a move.

The quality of visual information depends on the nature and characteristics of the view. Especially in dense urban environments where only the neighboring building is visible through the window, visual comfort is determined by the architectural elements that shape the façade and determine the aesthetic quality of what is seen. Façade materials with a combination of shapes, colors and textures facilitate a particular formal design [30]. A façade consists of a series structural or decorative elements and shapes that can be distinguished by the human eye through the rhythm of architectural elements. These include windows, which accentuate or calm elements in the composition; contrasts, which emphasize the variety of forms and motifs (e.g., dark-light, large-small, near-far contrasts), harmony, the balance of contrasts and similarities that determines the balance, coherence and functionality of the elements, and unity, which binds the elements into a coherent whole [33].

The results of the studies show that people are more satisfied when features are distant, and that when the landscape contained nature the effect of distance was smaller [8]. A suitable window view usually includes both the foreground and the horizon [34]. Bell and Burt [35] defined three "visible layers" in the window view: the upper layer (in the distance, containing the sky and the natural or artificial horizon), the middle layer (natural or artificial elements such as fields, trees, hills or buildings) and the lower layer (in the foreground, including vegetation and ground). Views that contain a variety of information are most appropriate, therefore all three visible layers are suggested as beneficial. The lower layer is particularly important as it provides visual information about the distance and thus the size of the objects in the middle layer.

In dense urban systems, the view from the windows of the middle floors includes only one, the middle layer, which provides very little information about the weather and the time of day. The fact is that the amount of sky and the presence of a leafy window box had direct positive effects on the assessment of recovery probability. Ground-level views with people and street trees elicit similar ratings as some views with sky, but views with the most sky were rated as the most restorative and popular [36]. Ko et al. [37] suggest considering at least two layers of landscape and/or sky when designing windows in dense urban structures. They also introduce dynamic features into window views in urban areas, 
e.g., traffic flow at a distance of more than $6 \mathrm{~m}$ from the window. Nearby movements (e.g., pedestrians passing in front of the window) can be distracting. In the analysis of psychological parameters [29] significant negative responses to the view were found in the tension-anxiety and anger-hostility subscales at middle floors compared to low floors. Significantly positive scores in the vitality subscale were found in low floors with abundant vegetation and in high floors with a view of the sky.

\subsection{Research Questions}

Numerous studies have focused on the positive effects of vegetation, compositional qualities and narrative. Some studies also justify the importance of distant views [8,9]. On the other hand, there are very few in-depth studies on the elements in the window view that trigger negative or poor reactions. There are also very few studies that address the issue of window views in a densely built environment, where only a close-up view of the neighboring building is possible. To fill this research gap, it is important to find out what causes negative reactions to certain window views. This question is particularly important in densely built urban areas where building patterns affect many people and have many impacts on the health and well-being of residents.

This research focuses on window views that are expected to elicit predominantly negative or bad reactions. Previous studies have shown that window views that are predominantly negatively evaluated often do not contain vegetation $[10,11,21]$. It can be assumed that the absence of vegetation is an important factor, but it is not only the absence of vegetation in the window view that can trigger negative reactions. This study focuses on other features in window views and examines them systematically. The study is designed as interdisciplinary because the user's reaction to the window view is not only a design problem for which the architect-designer is responsible, but also involves urban planning and landscape architecture, as well as socio-cultural aspects related to environmental perception. The core of the problem arises from the positioning of buildings in urban space, which is influenced by urban densification. For the user, this means that only the middle visible layer can be seen through the window, excluding the lower layer that makes visual contact with the ground and the upper layer that provides a view of distant objects and the sky. A questionnaire survey is used to determine the subjective reactions to looking out of the window at a nearby façade and to analyze the causes of these reactions. The homogeneity of groups of responses is tested using the Fischer-Snedercor test. The expected results will make it possible to define a set of design elements that can provoke negative reactions in the viewer and to which special attention should be paid in the design of façades. It will also be possible to link them to the results of other studies and to highlight the measures that planners can incorporate into the design of urban spaces and buildings to improve user perception.

\section{Research Hypothesis}

Although window views are an important element of architecture, there is no established framework for their design. Previous studies of window views show that the quality of the window view rated by the subjects is predicted by the viewing distance, the number of view layers, the quality of the landscape/elements and the composition of the view [38]. In terms of psychological influence, they focus mainly on the potential for restfulness $[5,10,20]$, comparisons between the restful effect of different natural and built scenes [12,19-21], and the influence of the type and proportion of façade vegetation on users' responses [8]. However, urban façades often do not contain green elements that otherwise have a positive effect on the viewer. In addition, urban densification reduces the distances between buildings, leaving only one visible layer in the window view. This not only restricts the inflow of natural light, but also impoverishes the quality of the view. The aim of this study is therefore to investigate people's perceptions and psychological responses to looking through a window at nearby façades with different visual qualities, 
where the view is restricted to only one layer. The hypotheses are thus linked to urban densification and the quality of the window view:

Hypothesis 1 (H1). Urban densification leads to an impoverishment of window views.

Hypothesis 2 (H2). Visual aesthetics is an imperative dimension of window views.

Hypothesis 3 (H3). Interventions can mitigate the negative impact of the lack of dynamic window views.

Based on previous research, the present study sought to identify the negative reactions of respondents to selected window views and the reasons for them. An additional aim of this study is to draw attention to the architectural elements in the window views that influence the negative reactions.

\section{Methods}

\subsection{Preliminary Research}

The study of reactions to window views of a nearby façade was conducted in two steps. In the first step, the pre-selection of window views was made. In the second step, the respondents' reactions to these views were studied and the reasons for the negative responses were analyzed. In this step, window views with similar characteristics were also identified. The analyzes of the baseline data using morphological and typological research methods, field observations and on-site analyzes include the following data:

- Geomorphological and real-estate data from the Surveying and Mapping Authority of the Republic of Slovenia [39]. Analyses of geomorphological features (topography, reliefs, terrain types and climate conditions, insolation, distances between buildings, etc.), real estate valuation (real estate register, valuation model register, real estate data from municipalities) and mapping of landscape features with spatial data using ArcGIS software (ArcMap version 10.3.1) for visual assessments and analyses.

- On site observations and analysis. Fieldwork and photographic surveys (AprilMay 2021).

For the purposes of this study, residential neighborhoods rather than individual buildings were observed, mainly because the relationship between buildings is an essential part of the view. In line with the aims of the study, cases were selected where buildings were at least five floors high, as this starting point provides a representative sample for understanding the relationship with the ground floor or the site. Due to the limited height, groups of shrubs and trees that enhance the ground floor space are no longer visible at this level [31]. In the survey views, window views were limited to the third and fourth floors, which can be seen through the window in terms of communication distance [40], horizontal field of view [26], architectural or environmental determinism [41] and human scale elements [26].

\subsection{Stimuli}

Close-up photographs of 20 window views of the nearby façade were selected for analysis. The selection deliberately excluded window views with elements that Ching [36] defines as positive or appropriate for achieving visual comfort. The photos were taken in residential neighborhoods in Ljubljana, Slovenia. The quality of the architecture was not assessed, so the selected buildings were not chosen as examples of appropriately or inappropriately designed or planned buildings, but as views of parts of the façades that were considered suitable for this study.

The views are selected so that the façades are approximately the same distance from the viewer, that they cover approximately the same viewing area and that they are photographed in similar light. The result of such an approach is that all views presented in the questionnaire are equidistant from the window and the window view covers two floors of 
the building opposite the viewer. Due to the close distance of the objects, the view includes only one visible layer (middle level). At the same time, this precludes the possibility of looking at all three visible layers, which Bell and Burt [38] recommend in order to achieve visual comfort. Looking through the window also does not provide information about the weather, time of day and location [42].

The façades were photographed on the same day (May 2021) and under the same weather conditions (cloudy day with diffuse light). To ensure sufficient variability, façades from different architectural periods were selected. The façades also contain different architectural and construction elements and are maintained differently. All photos were taken with the same camera and all images were resized to $480 \times 320$ pixels. The additional vegetation on five façades was created using Adobe Photoshop. No people are visible in any of the photographs in order to avoid their presence as a disturbing factor.

\subsection{Participants}

A total of 135 third year architecture students at the Faculty of Architecture, University of Ljubljana were invited to participate in the survey and 98 students responded to the survey, their average age 21.6 years. We hypothesize that architecture students are particularly sensitive to the recognition of visual features and architectural elements in window views, which is positive from a research perspective. Because of their prior education and inclination, it is also easier for them to argue the reasons for reactions to window views. However, the problem of close spacing between buildings, which leads to poor quality of window views, was not explained to them beforehand.

\subsection{Survey and Research Framework}

The questionnaire survey was voluntary and anonymous. It was published on the Moodle learning platform of the Faculty of Architecture at the University of Ljubljana on 20 May 2021 and was accessible for $24 \mathrm{~h}$. There was no time limit to complete the survey. The students who agreed to participate were asked to answer 52 questions. The questionnaire consisted of three parts: (1) The socio-demographic part dealt with the gender, age and type of settlement in which the respondents live. (2) The second part of the questionnaire contained questions about the type and size of the institution where the respondents live, what green spaces are available to them and how intensive their contact with nature is. (3) The third part of the questionnaire presented 20 photos of different window views, each with two questions. The first question was about the characteristics of the views. Respondents could choose from 11 possible answers/reactions (variable $X$ ), which were defined based on the previous experiences of researchers and case studies from the literature $[4,5,8,12,17,43,44]$. The second question was related to the reasons that triggered the reaction to the window view. Respondents could choose from seven possible answers/reasons (variable Y). The selected reasons were derived from the conceptual elements of visual aesthetics [36]. The possible reactions of the respondents and the reasons that triggered the responses are described in Table 1.

The differences between the reactions and the reasons were analysed using the most frequent answers (mode of specific answers, second and third most frequent answer) and the variability of the answers. The dispersion (variability) of the reactions was measured by the coefficient of variation, which is the standard deviation of the reactions normalized by the mean of the reactions. The homogeneity of the groups of reactions as well as groups of reasons was tested using the Fischer-Snedercor test. This study is mainly concerned with the results obtained in the third part of the survey. 
Table 1. The possible reactions of the respondents and the reasons that triggered the responses.

\begin{tabular}{|c|c|}
\hline Reaction (Variable X) & Reason (Variable Y) \\
\hline x1—frightening, scary, dangerous & y1-surface characteristic \\
\hline x2-incomprehensible, unpleasant & y2-composition quality \\
\hline x3-very disturbing, repellent, depressing & y3-narrative quality \\
\hline $\mathrm{x} 4$-boring & y4-complexity \\
\hline x5-soothing, pleasant & y5-dynamics \\
\hline x6-understandable, coherent, legible & y6-unpleasant/pleasant space \\
\hline x7-attractive, fascinating, invigorating & y7-other (can't define) \\
\hline \multicolumn{2}{|l|}{$\mathrm{x} 8$-dreamy, romantic } \\
\hline \multicolumn{2}{|l|}{ x9-mysterious } \\
\hline \multicolumn{2}{|l|}{ x10-acceptable, unobtrusive } \\
\hline x11-does not evoke a determined response, neutral & \\
\hline
\end{tabular}

\section{Results}

\subsection{Window View Perception Reactions}

The results show that the window views elicit different reactions from the respondents. Respondents tend to agree on pleasant, attractive and acceptable window views. For reactions $x 5$ - soothing, pleasant, $x 7$-attractive, fascinating, invigorating and $\times 10-$ acceptable, unobtrusive, the coefficient of variation ranged from 0.47 to 0.55 , while reactions x6-understandable, coherent, legible, x8 - dreamy, romantic, $x 9$ - mysterious and $\times 10-$ acceptable, unobtrusive were not selected. For window views with negative answers, x1-dangerous, frightening, scary, x2-incomprehensible, unpleasant, disturbing, x3-very disturbing, repellent, depressing, and $x 4$-boring, the reactions were less homogeneous, and the coefficient of variation was between 0.58 and 0.89 (see also Figure 1 ). The test of homogeneity of all responses for the window views with the most frequent responses $x 1-x 4$ and for the window views with the most frequent responses $x 5-x 11$ showed that there was a difference between the variation of the two groups of reactions $(\mathrm{F}=0.827 ; \alpha=0.003)$.

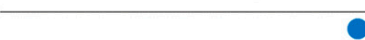

0.4

0.2

positive reactions

0.0

$\begin{array}{llllllllllll}\mathrm{x} 1 & \mathrm{x} 2 & \mathrm{x} 3 & \mathrm{x} 4 & \mathrm{x} 5 & \mathrm{x} 6 & \mathrm{x} 7 & \mathrm{x} 8 & \mathrm{x} 9 & \mathrm{x} 10 & \mathrm{x} 11\end{array}$

Figure 1. Cont. 


\begin{tabular}{|c|c|c|c|}
\hline Reaction (Variable X) & $\begin{array}{c}\text { Standard } \\
\text { Deviation }\end{array}$ & Average & $\begin{array}{l}\text { Coefficient } \\
\text { of Variation }\end{array}$ \\
\hline $\mathrm{x} 1$ - frightening, scary, dangerous & 2.523 & 2.827 & 0.893 \\
\hline x2-incomprehensible, unpleasant & 3.117 & 4.541 & 0.687 \\
\hline $\mathrm{x} 3$ - very disturbing, repellent, depressing & 2.505 & 3.829 & 0.654 \\
\hline $\mathrm{x} 4$ - boring & 2.606 & 4.467 & 0.583 \\
\hline$x 5-$ soothing, pleasant & 2.984 & 6.286 & 0.475 \\
\hline x6-understandable, coherent, legible & NA & NA & NA \\
\hline$x 7$ - attractive, fascinating, invigorating & 3.004 & 5.5 & 0.546 \\
\hline $\mathrm{x} 8$ - dreamy, romantic & NA & NA & NA \\
\hline$x 9-$ mysterious & NA & NA & NA \\
\hline x10 - acceptable, unobtrusive & 2.967 & 6.523 & 0.455 \\
\hline $\begin{array}{l}\text { x11 - does not evoke a determined response, } \\
\text { neutral }\end{array}$ & NA & NA & NA \\
\hline
\end{tabular}

Figure 1. Coefficient of variation of respondent's reactions and data used for calculation of coefficient of variation.

Figure 2 shows the 20 window views included in the survey, the most frequent reactions, the proportion of responses with negative reactions (reactions $x 1-x 4$ ) and the coefficient of variation of the reactions. Respondents gave a negative reaction for $12(60 \%)$ window views. The data in the figure also show that window views with predominantly negative reactions elicit divided opinions about the reasons for these opinions, as the dispersion of reactions is higher (the coefficient of variation is between 0.58 and 0.89 ); for window views with predominantly negative reactions, the reasons are much more uniform (the coefficient of variation is between 0.46 and 0.55 ).

A detailed review of the reactions to the window views for which respondents most frequently provided reaction codes $x 1-x 4$ reveals some interesting features. Of the 12 window views, window view 9 elicited a consistent reaction, with $87.8 \%$ of respondents believing it to be frightening, scary and dangerous (reaction $\times 1$ ). The window view includes older, poorly maintained façade with a damaged rendered surface, which was defined as the feature most likely to elicit unpleasant feelings. Window views 14 and 16 elicited a negative response, mainly due to incomprehensibility or unpleasantness (reaction $\mathrm{x} 2$ ). These two window views consist of different architectural elements (balconies, fences, beams and columns) and their composition is incomprehensible and irregular. The four window views (window views 3, 8, 11 and 18) are found to be very disturbing, repellent, depressing (reaction $\times 3$ ). For these window views, the reasons for the reactions are the compositional quality, poor maintenance, intricate geometry and dynamic coloring. However, five window views were described as boring by respondents; these window views are numbered 1 , $5,12,15$ and 20 . 


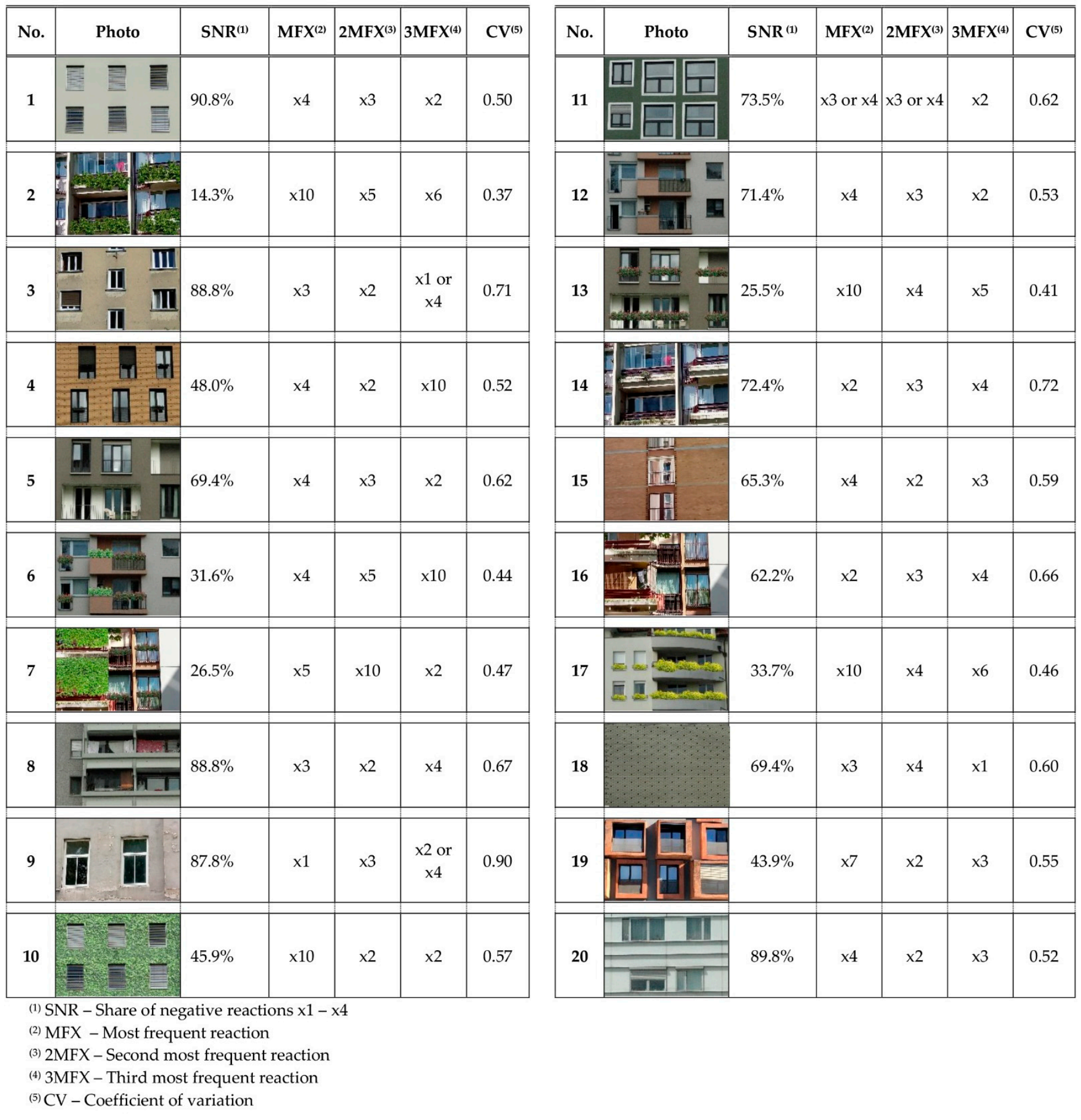

Figure 2. Window views and respondents' reactions (code for reaction: $x 1$-dangerous, frightening, scary; $x 2$-incomprehensible, unpleasant, disturbing; $x 3$-very disturbing, repellent, depressing; x4-boring; x5-soothing, pleasant; x6-understandable, coherent, legible; x7—attractive, fascinating, invigorating; x8-dreamy, romantic; x9-mysterious; x10-acceptable, unobtrusive; x11-does not evoke any specific response, neutral).

\subsection{Reasons for the Negative Perception of Window Views}

The reasons for the predominantly negative reactions to window views can be further identified through detailed analysis of the responses. Figure 3 shows the three most frequent responses to the reasons given by 98 respondents. 


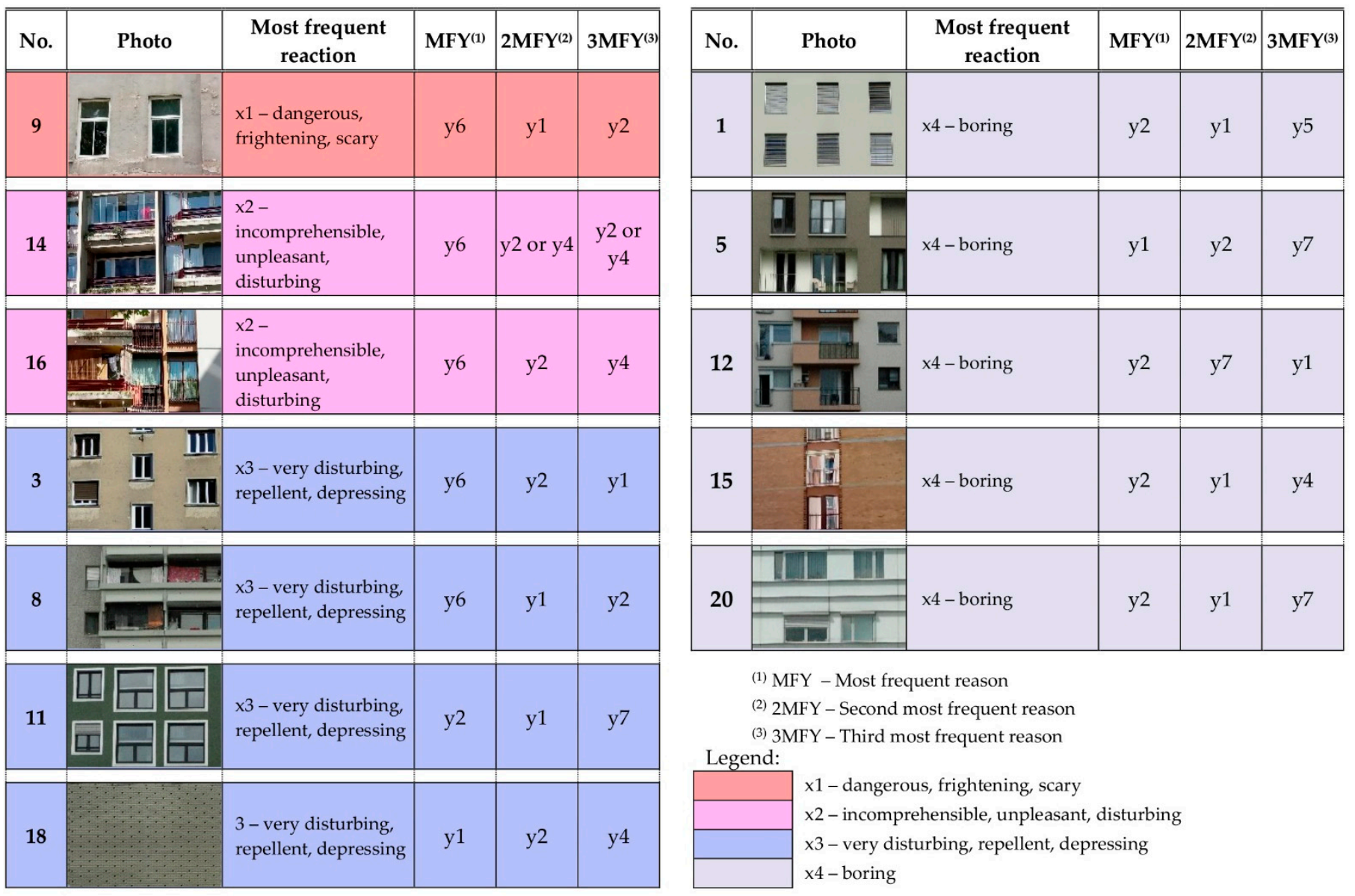

Figure 3. Window views with a predominantly negative reaction and the reason for the reaction (code for reason: y1-surface characteristic (e.g., colors, texture), y2-composition quality (good or bad, e.g., position and proportions of the elements), y3-narrative quality (e.g., involuntary attention, suggestiveness), y4—complexity (e.g., singularity in form, details), y5—dynamic (e.g., degree of vegetation, human activities in opposite buildings), y6 - unpleasant/pleasant space (e.g., maintenance, safety, health, compatibility, unity), y7-other (can't define).

Figure 4 shows the reasons for perceiving window views in a relative number of responses. The reasons for perceiving the window view as frightening, scary, dangerous (reaction $\mathrm{x} 1$ ) and incomprehensible, unpleasant (reaction $\mathrm{x} 2$ ) are mainly its maintenance (reason y6); other reasons are its characteristic texture (reason y1), compositional quality (reason y2) and complexity (reason y4). All these reasons also define the window view as very disturbing, repellent, depressing (reaction $\times 3$ ). When defining a window view as boring (reaction $\mathrm{x} 4$ ), its narrative can be added to the reason (reason y3), although the main reason for a boring window view is its compositional quality (reason y2). 


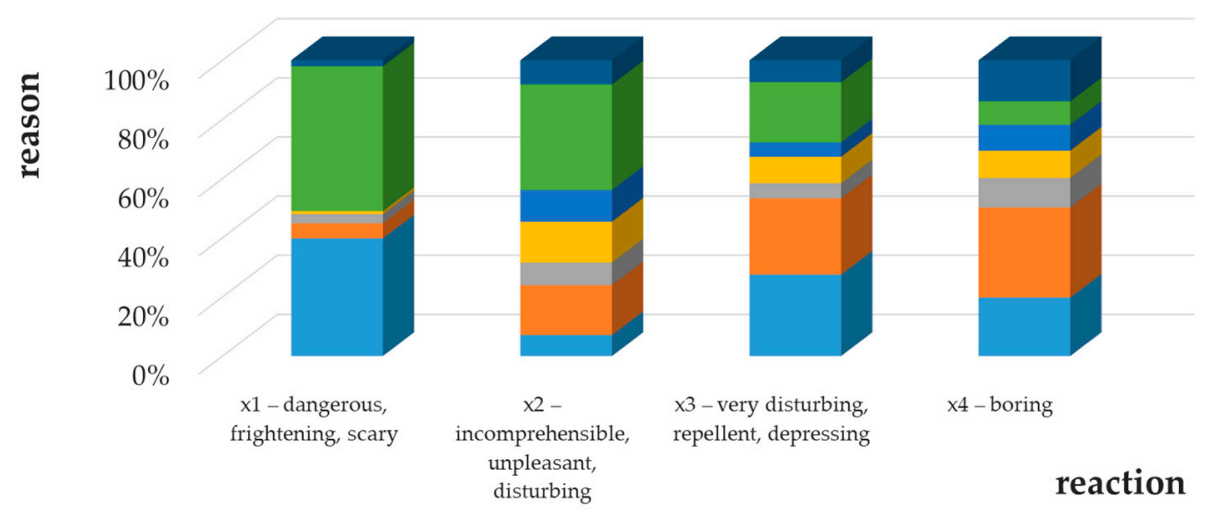

y7 - other (I can't define myself)

y6 - unpleasant / pleasant space (e.g. maintenance, safety, health, compatibility, unity)

घ5 - dynamic (e.g. degree of greenery, human activities in opposite buildings)

- y4 - complexity (e.g. singularity in form, details)

- y3 - narrative quality (e.g. involuntary attention, suggestiveness)

y2 - composition quality (good or bad, e.g. position and proportions of the elements)

y1 - surface characteristic (e.g. colours, texture)

\begin{tabular}{|c|c|c|c|c|}
\hline Reaction (X) & $\begin{array}{c}\mathrm{x} 1- \\
\text { Dangerous, } \\
\text { frightening, } \\
\text { scary }\end{array}$ & $\begin{array}{l}\text { x2 - Incom- } \\
\text { prehensible, } \\
\text { unpleasant, } \\
\text { disturbing }\end{array}$ & $\begin{array}{c}\text { x3-Very } \\
\text { disturbing, } \\
\text { repellent, } \\
\text { depressing }\end{array}$ & $x 4$ - Boring \\
\hline y1 - surface characteristic & $39.8 \%$ & $7.1 \%$ & $27.6 \%$ & $19.8 \%$ \\
\hline y2 - composition quality & $5.1 \%$ & $16.8 \%$ & $25.8 \%$ & $30.4 \%$ \\
\hline y3 - narrative quality & $3.1 \%$ & $7.7 \%$ & $5.1 \%$ & $10.0 \%$ \\
\hline y4-complexity & $1.0 \%$ & $13.8 \%$ & $8.9 \%$ & $9.2 \%$ \\
\hline y5-dynamic & $0 \%$ & $10.7 \%$ & $4.8 \%$ & $8.8 \%$ \\
\hline $\begin{array}{l}\text { y6-unpleasant / pleasant } \\
\text { space }\end{array}$ & $49.0 \%$ & $35.7 \%$ & $20.4 \%$ & $8.0 \%$ \\
\hline $\begin{array}{l}\text { y7 - other (I can't define my- } \\
\text { self) }\end{array}$ & $2.0 \%$ & $8.2 \%$ & $7.4 \%$ & $13.9 \%$ \\
\hline
\end{tabular}

Figure 4. Reactions and reasons for the predominantly negative perception of the window view.

\section{Discussion}

This study attempts to answer the important question of how a shorter viewing distance affects the observer. This question is not only important for daylighting, but also in the context of sustainable development, as it encompasses many aspects, from health and well-being to environmental impact and efficiency. In line with to the principles of compact cities, public open space will be further reduced in the future, leading to an increase in building density and a reduction in distances between buildings. When considering the relationship of windows to outdoor views and urban density, it becomes clear that the density of the building refers to the reduction of view width and the loss of three visible layers in the sense of the principal of view, series of views and openness to space. The first visible layer (ground floor view) loses width and the middle layer (building level) is limited to the view of the nearby façade and becomes the main focus when approaching the neighboring building. Studies have shown that window views containing distant elements are generally preferred [8]. Reducing the distance between buildings also reduces the possibility of the view going wide and losing some or all of the quality of the middle visible layer provided by the view of the landscape (the background of the building). In this context, we were particularly interested in whether the reduced distance is a key factor influencing the reviewers' reactions and whether other features such as aesthetics and dynamics of the window view also have a noticeable influence.

\subsection{Distance of Window View}

Previous work has shown that the proportion of the façade or object obtained in the field of view is an important issue. For the horizontal field of view [26], the study 
considered five-storey block buildings, which are the common typology in residential block development concepts. The closer the observed object gets, the smaller the viewing angle becomes. If the observed building is a horizontal block, the façade may obscure the entire field of view, which was the case in this study. When understanding the idea of urban concepts (organic, network, linear, etc.), the question of the concept of general compatibility also relates to the social background, namely the community. The "active façade" created by programs, users and additional street furniture (lights, billboards, additional elements in terms of temporary use of space) is an important co-designer of urban space. From the perspective of supporting the concept of human scale, the active façade incorporates the importance of the criteria that were the basis of this research: perception of height (the gaze captures elements of the façade up to a height of five floors), relationship of the façade and the open space and relative to the viewing angle (the further away the observed façade, the more added elements of all three visible layers are captured). In this sense, elements of greenery have been added to some real examples of window views. These elements deny the concept of monotony, defined in the study as "boredom", and the need for diversity at the level of urban concepts with measurable quantitative criteria (use, building, spaciousness, density, insularity) and non-measurable or qualitative criteria (accessibility, flexibility, importance of space, vitality). Nevertheless, five window views were defined as "boring" in the study and compositional quality (y2) and narrative (y3) were defined as the main reasons. The analysis of these cases showed that they mainly lacked the above mentioned characteristics.

The façade views in the study focused on the third and fourth floors of the selected case buildings and were chosen to allow only a view of a few windows of the opposite façade without any other visible layers. Restricting the view to the middle visible layer significantly reduced the amount of information that the open outdoor space. It was to be expected that the respondents' reactions to most of the window views would be quite poor. This was based on the conclusions of previous studies in which window views with distant elements were generally considered positive [8,45-47]. However, the results of this study show that respondents did not react similarly to all window views in the survey. While more than half of the window views received rather negative responses, the remaining window views were rated positively. Respondents were more likely to agree on pleasant, attractive and acceptable window views than on unpleasant and incomprehensible window views (Figure 1). In particular, window views that contained certain features such as an interesting composition and greenery were rated quite positively. The results suggest that building distance is an important but not the only determining factor for a certain type of response, and that other factors such as visual aesthetics and maintenance may also be important.

\subsection{Aesthetics of Window View}

The studies suggest that visual aesthetics is an important dimension of the noninstrumental qualities of window views that influence users' emotional response and perception. Furthermore, some authors have already found that certain views can elicit positive responses, while others can have neutral or even negative effects [48]. This comes to the fore especially when there are no other features such as dynamism and variability in the view that could mitigate certain negative effects. This was confirmed by the results of this study. Respondents repeatedly chose typical causes for the negative reactions; in particular, surface characteristics (y1) was chosen as the main reason for negative reactions. This often occurred in relation to window views with strong color contrasts and textures (e.g., window views 5, 11 and 14, which were considered disturbing), but also window views with uniform geometry and monotonous coloring (e.g., window view 1 , which was rated as boring). It should be emphasized that surface characteristics can be interpreted in different ways, e.g., as texture quality and color or as a result of maintenance. Respondents ${ }^{\prime}$ answers were heterogeneous in this case, so it is not possible to determine exactly what the disturbing feature was in the window views. However, we note that the results of the study 
are consistent with the findings of other authors who argue that views with articulated colors, textures and patterns are more complex [17]. The effect on the viewer's mood must also be considered, as specific, interesting features in the view may elicit different emotional responses than general, undefined or uninteresting views [44] and the view of specific features may elicit corresponding psychological responses [17]. As these effects are linked to the individual experiences of the respondents, it becomes even more difficult to determine the effects of a specific feature in a window view.

The second most common reason that triggered negative responses was the quality of the composition (y2). Window views that received negative scores can be defined as compositionally incoherent because they lack proportional quality (e.g., harmonious alignment and hierarchy of architectural elements) [36]. One could argue that the responses are mainly due to the professional orientation of the respondents. However, this result aligns well with previous studies showing that people in urban environments are uncomfortable with incoherent, illegible and complex views [17] and enjoy views that provide some degree of intelligibility [5]. Studies also show that the diversity of psychophysiological responses is influenced not only by complexity, but also by openness and spatial definition $[16,36]$.

The third most common reason respondents used to express a negative reaction was unpleasant space (y6), which was particularly articulated in window views with poorly maintained surfaces. This is not in itself a consequence of compositional quality, but can have an impact if the building deteriorates and the viewer loses a sense of security, order and intelligibility as a result [6]. In the study, reactions related to poor maintenance were quite coherent and consistent, so it is very safe to assume that respondents would react accordingly in other similar cases. As previous studies have also found that people in poorly maintained urban environments feel uncomfortable and have a greater sense of danger $[17,49]$, it is reasonable to assume that poorly maintained buildings can indeed create perceptions of insecurity, poor health, lack of compatibility and uniformity.

\subsection{Dynamics in the Window View}

The urban layout is important for the perception of the façade view. If the urban ground plan forms a uniform rectangular pattern, this leads to a parallel positioning between the viewer and the observed. The view through the window is centered and frontal on the façade, resulting in a static arrangement. In an irregular urban design, the window views have an uneven angle of view, which is perceived as dynamic. In contrast to the urban design approach, which very clearly emphasizes the need for diversity with measurable quantitative criteria in urban design, it is noted that at the level of façade design, both monotony and pronounced diversity can be disturbing factors (Figure 2). The study assumed that the negative effects of both factors can be mitigated by certain measures. In doing so, we drew on the findings of some authors who have found that urban environments that contain natural elements have positive effects on users [50,51]. In particular, it was important to find out whether adding certain simple elements, especially vegetation, could change the negative perception of some window views. The survey responses confirmed these assumptions, as respondents consistently reacted negatively to the original views (without vegetation) and significantly more positively to the same views with vegetation added (window views 2, 6, 7, 10 and 13). In general, these results confirm the findings of other studies that consider vegetation to be an extremely positive factor [31]. In addition, the effects of the different vegetation features were defined more precisely in this study. In particular, large areas of vegetation on the façade were found to be effective in concealing untidy and poorly maintained parts of the building, thus reducing the perception of dangerous, intimidating, incomprehensible and unpleasant window views. Similarly, window views that are perceived as disturbing, repellent and depressing. In these cases, the added vegetation has increased the dynamism and coherence of the window view, improving interest and consistency.

With regard to the above findings, the coherence and scope of the green elements must be considered. During the preparation of the survey, it was noted that the greening 
of façades is mainly due to individual interventions by residents, which are spatially limited and do not involve large and elaborate interventions. Increased complexity and inconsistency of the view by adding different green elements could therefore be ineffective or even have a negative impact. This was also evident in the window view 6, which was perceived as boring by most respondents despite the flowerpots on the balconies (Figure 2). In this context, the concept of general compatibility that relates to social background, namely the "active façade", should be mentioned again. Green elements, as suggested in the survey, have undoubtably reduced the perception of monotony. In the future, these and similar problems should be addressed in a more organized way, e.g., within sustainable approaches such as biophilic architecture or community activities, and not left solely to the initiative of individual residents.

\section{Conclusions}

The most important contribution of this study is that it has defined more precisely the effects of certain features in window views on observers. The study of the perception of different window views takes into account the principles of sustainable design and the principles that show that the design of façade elements is not only a problem of architecture, but also affects other fields such as construction and urban planning. It should also be emphasized that this issue needs to be considered from a multi-layered perspective, especially the perspective of urban scale, design of the architectural envelope and user experience:

- In the context of urban space, the way of interpreting the results according to "problems mapped by spatial scale" is summarized in terms of "spatial scale: built form" and "sustainable goals: human needs". Urban densification naturally follows the principles of the concepts of compact cities, in which density is one of the most important planning issues that can regularly lead to all kinds of misunderstandings and tensions, but is an essential driver for our urban future. The study has undoubtedly found that urban densification leads to an impoverishment of window views, but it is not the only determining factor. In this context, urban density does not mean the number of people inhabiting a given urbanized area, but urban intensification in the sense of denser development with less open space. Yet the balance between of built and open space should better follow the principles of sustainable development in the sense of "high density without intensity". Above all, we need to make a clear distinction between desirable compact city living and the other word that urban planners try to avoid: overcrowding [52].

- It has been shown that visual aesthetics are an important dimension of window view. In particular, features such as compositional quality, maintenance and dynamics have been found to be important. The fact is that a large part of the population spends most of its time indoors. This type of work and lifestyle have increased during the COVID-19 epidemic and will remain so afterwards [18]. We can assume that the students surveyed also spend most of their time indoors, working with devices that require them to focus on nearby objects. This involves constant use of visual displays, such as computer screens or mobile phones, which increases the need for a good view out of the window. However, the specific population studied allowed some characteristics of the window view (e.g., compositional quality and color scheme) to be defined more precisely.

- Furthermore, it was found that interventions into façades can increase the dynamics of the window view. In particular, large, uniform green elements had a mitigating effect on the viewer and were found to be more effective than small and varied elements.

The findings can help to understand and predict user reactions better and can add new qualities to urban planning and architectural design. In the wider context, they can also support efforts to find innovative ways to solve current problems. 


\begin{abstract}
Author Contributions: Conceptualization, M.Z.-S. and A.F.; Methodology, M.Z.-S., S.D. and Ž.K.; Software, S.D.; Formal analysis, M.Z.-S., Ž.K., L.K. and S.D.; Data collection, M.Z.-S., L.K. and Ž.K.; Writing—original draft preparation, M.Z.-S., A.F., S.D. and Ž.K.; Writing—review and editing, Ž.K., M.Z.-S.; Visualization, L.K.; Supervision, M.Z.-S. All authors have read and agreed to the published version of the manuscript.
\end{abstract}

Funding: This research was funded by Slovenian Research Agency, by Research Program "Sustainable planning for the quality living space" (P5-0068), by Research Program "Earth observation and geoinformatics" (P2-0406), and by Research Project "Creating social value with age-friendly housing stock management in lifetime neighborhoods" (J5-1784).

Institutional Review Board Statement: Not applicable.

Informed Consent Statement: Not applicable.

Conflicts of Interest: The authors declare no conflict of interest.

\title{
References
}

1. Rodriguez, F.; Garcia-Hansen, V.; Allan, A.; Isoardi, G. Subjective responses toward daylight changes in window views: Assessing dynamic environmental attributes in an immersive experiment. Build. Environ. 2021, 195, 107720. [CrossRef]

2. Butler, D.L.; Biner, P.M. Effects of setting on window preferences and factors associated with those preferences. Environ. Behav. 1989, 21, 17-31. [CrossRef]

3. Stone, N.J.; Irvine, J.M. Direct or indirect window access, task type, and performance. J. Environ. Psychol. 1994, 14, 57-63. [CrossRef]

4. Kim, U.; Wineman, J. Are Windows and Views Really Better? A Quantitative Analysis of the Economic and Psychological Value of Windows; Working Paper; Taubman College of Architecture and Urban Planning, University of Michigan: Ann Abor, MI, USA, 2005; Available online: http:/ / www.lrc.rpi.edu/programs/daylighting/pdf/viewreport1.pdf (accessed on 26 October 2021).

5. Kaplan, R.; Kaplan, S. The Experience of Nature: A Psychological Perspective; Cambridge University Press: Cambridge, UK, 1989; Available online: https:/ /archive.org/details/experienceofnatu00kapl (accessed on 24 October 2021).

6. Ulrich, R.S. View through a window may influence recovery from surgery. Science 1984, 224, 420-421. [CrossRef] [PubMed]

7. Chang, C.C.; Oh, R.R.Y.; Nghiem, L.T.P.; Zhang, Y.; Tan, C.L.Y.; Lin, B.B.; Gaston, K.J.; Fuller, R.A.; Carrasco, L. Life satisfaction linked to the diversity of nature experiences and nature views from the window. Landsc. Urban Plan. 2020, 202, 103874. [CrossRef]

8. Kent, M.; Schiavon, S. Evaluation of the effect of landscape distance seen in window views on visual satisfaction. Build. Environ. 2020, 183, 107160. [CrossRef]

9. Yeom, S.; Kim, H.; Hong, T.; Park, H.S.; Lee, D.-E. An integrated psychological score for occupants based on their perception and emotional response according to the windows' outdoor view size. Build. Environ 2020, 180, 107019. [CrossRef]

10. Kang, Y.; Kim, E.J. Differences of Restorative Effects While Viewing Urban Landscapes and Green Landscapes. Sustainability 2019, 11, 2129. [CrossRef]

11. Kley, S.; Dovbishchuk, T. How a Lack of Green in the Residential Environment Lowers the Life Satisfaction of City Dwellers and Increases Their Willingness to Relocate. Sustainability 2021, 13, 3984. [CrossRef]

12. Elsadek, M.; Liu, B.; Lian, Z. Green façades: Their contribution to stress recovery and well-being in high-density cities. Urban For. Urban Green. 2019, 46, 126446. [CrossRef]

13. Ko, W.H.; Brager, G.; Schiavon, S.; Zhang, H.; Graham, L.T.; Brager, G.; Mauss, I.; Lin, Y.W. The impact of a view from a window on thermal comfort, emotion, and cognitive performance. Build. Environ. 2020, 175, 106779. [CrossRef]

14. Kaplan, R. The Nature of the View from Home: Psychological Benefits. Environ. Behav. 2001, 33, 507-542. [CrossRef]

15. Kaplan, R. The role of nature in the context of the workplace. Landsc. Urban Plan. 1993, 26, 193-201. [CrossRef]

16. Ozdemir, A. The Effect of Window Views' Openness and Naturalness on the Perception of Rooms' Spaciousness and Brightness: A Visual Preference Study. Sci. Res. Essays 2010, 5, 2275-2287. Available online: https://www.semanticscholar.org/paper/ The-effect-of-window-views-openness-and-naturalness-Ozdemir/c6e733b2b98173603f016fe47e2f9e128b493425 (accessed on 10 November 2021).

17. Van Esch, E.; Minjock, R.; Colarelli, S.M.; Hirsch, S. Office window views: View features trump nature in predicting employee well-being. J. Environ. Psychol. 2019, 64, 56-64. [CrossRef]

18. Spano, G.; D’Este, M.; Giannico, V.; Elia, M.; Cassibba, R.; Lafortezza, R.; Sanesi, G. Association between indoor-outdoor green features and psychological health during the COVID-19 lockdown in Italy: A cross-sectional nationwide study. Urban For. Urban Green. 2021, 62, 127156. [CrossRef] [PubMed]

19. Ulrich, R.S. Visual landscapes and psychological wellbeing. Landsc. Res. 1979, 4, 17-23. [CrossRef]

20. Laumann, K.; Gärling, T.; Morten Stormark, K. Rating scale measures of restorative components of environments. J. Environ. Psychol. 2001, 21, 31-44. [CrossRef]

21. Laumann, K.; Gärling, T.; Stormark, K.M. Selective attention and heart rate responses to natural and urban environments. J. Environ. Psychol. 2003, 23, 125-134. [CrossRef]

22. Tennessen, C.M.; Cimprich, B. Views to nature: Effects on attention. J. Environ. Psychol. 1995, 15, 77-85. [CrossRef] 
23. Skärbäck, E.; Björk, J.; Stoltz, J.; Rydell-Andersson, K.; Grahn, P. Green Perception for well-Being in Dense Urban Areas-A Tool for Socioeconomic Integration. Nord. J. Archit. Res. 2014, 2, 179-200. Available online: https://www.researchgate.net/ publication/269405003_Green_perception_for_well-being_in_dense_urban_areas_-_a_tool_for_socioeconomic_integration\# fullTextFileContent (accessed on 29 October 2021).

24. Mladenovič, L. Kriteriji za Trajnostno Načrtovanje in Gradnjo Območij z Visoko Gostoto Poselitve. Ph.D. Thesis, Faculty of Architecture, University of Ljubljana, Ljubljana, Slovenia, 2011.

25. Čok, G. Residential Buildings and Sustainable Development in Slovenia. Prostor 2014, 22, 134-147. Available online: http: / / hrcak.srce.hr/index.php?show=clanak\&id_clanak_jezik=183572 (accessed on 8 November 2021).

26. Gehl, J.; Kaefer, L.J.; Reigstad, S. Close encounters with buildings. Urban Des. Int. 2006, 11, 29-47. [CrossRef]

27. Fouchier, V.; Merlin, P. (Eds.) High Urban Densities: A Solution for Our Cities; Consulate General of France in Hong Kong: Hong Kong, 1994.

28. Dimitrovska Andrews, K. Orodja za Usmerjanje in Nadzor Urbanih Oblik; Urbanistični Inštitut Republike Slovenije: Ljubljana, Slovenia, 2011.

29. Jeon, S.M.; Kang, M.; Kim, S.J.; Kim, Y.J.; Choi, H.B.; Lee, J. Psychological and Physiological Responses to Different Views through a Window in Apartment Complexes. J. People Plants Environ. 2021, 24, 545-550. [CrossRef]

30. Grütter, J.K. Basics of Perception in Architecture; Springer: Wiesbaden, Germany, 2015.

31. Schmid, H.-L.; Säumel, I. Outlook and insights: Perception of residential greenery in multistorey housing estates in Berlin, Germany. Urban For. Urban Green. 2021, 63, 127231. [CrossRef]

32. Elsadek, M.; Liu, B.; Xie, J. Window view and relaxation: Viewing green space from a high-rise estate improves urban dwellers wellbeing. Urban For. Urban Green. 2020, 55, 126846. [CrossRef]

33. Ching, F.D.K. Architecture: Form, Space, E Order, 4th ed.; John Wiley \& Sons: Hoboken, NJ, USA, 2015.

34. Littlefair, P.J. Designing with Innovative Daylighting; IHS BRE Press: Watford, UK, 1996.

35. Bell, J.; Burt, W. Designing Buildings for Daylight; Construction Research Communications Ltd.: London, UK, 1995.

36. Masoudinejad, S.; Hartig, T. Window View to the Sky as a Restorative Resource for Residents in Densely Populated Cities. Environ. Behav. 2020, 52, 401-4361. [CrossRef]

37. Ko, W.H.; Kent, M.G.; Schiavon, S.; Levitt, B.; Betti, G. A window view quality assessment framework. LEUKOS 2021, in press. [CrossRef]

38. Szybinska Matusiak, B.; Klöckner, C.A. How we evaluate the view out through the window. Archit. Sci. Rev. 2016, 59, 203-211. [CrossRef]

39. Ministry of Environment and Spatial Planning, Surveying and Mapping Authority of the Republic of Slovenia. E-Suraying Data. Available online: https://www.gov.si/en/state-authorities/bodies-within-ministries/surveying-and-mapping-authority/ (accessed on 25 April 2020).

40. Hall, E.T. The Hidden Dimension; Doubleday: New York, NY, USA, 1966.

41. Carmona, M.; Tiesdell, S.; Heath, T.; Oc, T. Urban Spaces-Public Places: The Dimensions of Urban Design; Architectural Press: Oxford, UK, 2003.

42. SIST EN 17037: 2019. Daylight of Buildings. Available online: https://standards.iteh.ai/catalog/standards/sist/6fd9e65f-c3ba4cda-a69c-dcbd8b7dce8d/sist-en-17037-2019 (accessed on 10 October 2021).

43. Brown, D.K.; Barton, J.L.; Gladwell, V.F. Viewing Nature Scenes Positively Affects Recovery of Autonomic Function Following Acute-Mental Stress. Environ. Sci. Technol. 2013, 47, 5562-5569. [CrossRef]

44. Aries, M.B.C.; Veitch, J.A.; Newsham, G.R. Windows, view, and office characteristics predict physical and psychological discomfort. J. Environ. Psychol. 2010, 30, 533-541. [CrossRef]

45. Portello, J.K.; Leon, A. Computer-related visual symptoms in office workers. Ophthalmic Physiol. Optic. 2012, 32, 375-382. [CrossRef] [PubMed]

46. Long, J.; Cheung, R.; Duong, S.; Paynter, R.; Asper, L. Viewing distance and eyestrain symptoms with prolonged viewing of smartphones. Clin. Exp. Optom. 2017, 100, 133-137. [CrossRef] [PubMed]

47. Thomson, W.D. Eye problems and visual display terminals-the facts and the fallacies. Ophthalmic Physiol. Opt. J. Br. Coll. Ophthalmic Opt. Optom. 1998, 18, 111-119. [CrossRef]

48. Martens, D.; Gutscher, H.; Bauer, N. Walking in "wild" and "tended" urban forests: The impact on psychological well-being. J. Environ. Psychol. 2011, 31, 36-44. [CrossRef]

49. Herzog, T.R.; Chernick, K.K. Tranquility and danger in urban and natural settings. J. Environ. Psychol. 2000, 20, 29-39. [CrossRef]

50. Tenngart Ivarsson, C.; Hagerhall, C. The perceived restorativeness of gardens-Assessing the restorativeness of a mixed built and natural scene type. Urban For. Urban Green. 2008, 7, 107-118. [CrossRef]

51. Subiza-Pérez, M.; Pasanen, T.; Ratcliffe, E.; Lee, K.; Bornioli, A.; de Bloom, J.; Korpela, K. Exploring psychological restoration in favorite indoor and outdoor urban places using a top-down perspective. J. Environ. Psychol. 2021, 78, 101706. [CrossRef]

52. Lehmann, S. Sustainable urbanism: Towards a framework for quality and optimal density? Future Cities Environ. 2016, 2, 8. [CrossRef] 